\title{
Laboreal
}

Volume $13 \mathrm{~N}^{\circ} 1$ | 2017

Varia

\section{O que é uma aptidão profissional?}

¿Qué es una aptitud profesional?

Qu'est-ce qu'une aptitude professionnelle?

What is an occupational skill?

\section{Jean-Maurice Lahy}

Tradutor. João Viana Jorge

\section{(2) OpenEdition}

\section{Journals}

\section{Edição electrónica}

URL: http://journals.openedition.org/laboreal/2001

DOI: 10.4000/laboreal.2001

ISSN: 1646-5237

\section{Editora}

Universidade do Porto

\section{Refêrencia eletrónica}

Jean-Maurice Lahy, «O que é uma aptidão profissional? », Laboreal [Online], Volume 13 Nº1 | 2017,

posto online no dia 01 julho 2017, consultado o 24 setembro 2020. URL : http://

journals.openedition.org/laboreal/2001; DOI : https://doi.org/10.4000/laboreal.2001

Este documento foi criado de forma automática no dia 24 setembro 2020.

\section{c) (i) (8)}

Laboreal está licenciado com uma Licença Creative Commons - Atribuição-NãoComercial 4.0 Internacional. 


\title{
O que é uma aptidão profissional?
}

\author{
¿Qué es una aptitud profesional? \\ Qu'est-ce qu'une aptitude professionnelle? \\ What is an occupational skill?
}

Jean-Maurice Lahy

Tradução : João Viana Jorge

\section{REFERÊNCIA}

Texto original: Lahy, J.-M. (1922). Qu'est-ce qu'une aptitude professionnelle ? III ${ }^{\mathrm{e}}$ conférence internationale de psychotechnique appliquée à l'orientation professionnelle, Milan, 24 octobre 1922, Atti della III ${ }^{\mathrm{e}}$ conferve internazionale de psicotecnica applicata al orientamento profesionale, Milan, Società umanitaria.

1 A ideia de proceder à orientação profissional da juventude venceu atualmente todas as resistências. Concorda-se com a necessidade de não mais deixar ao acaso a escolha da profissão, e pelo contrário substituí-lo pela determinação racional das carreiras para onde se devem encaminhar os adolescentes.

Ora apesar desta unanimidade das opiniões a questão não progride de todo. Especulando sobre a imprecisão dos termos «orientação profissional» muitos querem aproveitar-se do movimento de opinião que se cria para proceder, em proveito de determinadas industrias, à distribuição da mão-de-obra juvenil. Quer dizer que, preocupando-se unicamente com as exigências do mercado local, contam oferecer às crianças, não as profissões em que poderiam ser bem sucedidas mas aquelas em que se faz sentir a necessidade de mão-de-obra.

Digamos antes de tudo que na nossa opinião estes dois interesses: o interesse do futuro aprendiz e o dos empregadores, não deviam opor-se mas conjugar-se. Com efeito, se a orientação profissional for bem conduzida deve levar a um recrutamento de trabalhadores de elite para cada profissão e fornecer um emprego a cada trabalhador. A considerar a questão sob um só dos seus aspetos chegar-se-á fatalmente ao fracasso e ao 
descrédito da orientação profissional sem nada mudar - nem do ponto de vista social, nem do ponto de vista individual - à vigente ordem das coisas.

Pensamos que esta divergência de opiniões vem mais da maneira imprecisa como a questão foi colocada do que de uma hostilidade sistemática da parte dos empregadores.

Com efeito, enquanto determinadas organizações dirigem em vão a orientação profissional para a simples distribuição de mão-de-obra juvenil, grupos de industriais e comerciantes puseram-se em contacto com psicofisiologistas e instrutores esclarecidos por compreenderem todo o interesse que há em assentar a orientação profissional em bases científicas.

Que se nos permita citar, entre as tentativas mais bem sucedidas, a de «Escola na Oficina ». O seu comité formado por membros do ensino e por industriais que sustentam financeiramente a criação de um Gabinete de orientação profissional pretende que a pesquisa das aptidões das crianças deve prosseguir paralelamente à das condições do mercado de trabalho.

7 Aliás, os partidários das duas teses - orientação profissional e distribuição da mão-deobra juvenil - acordaram em reconhecer que é preciso fazer apelo às aptidões das crianças. Mas enquanto os primeiros têm da coisa uma noção precisa, para os outros resume-se numa simples formulação verbal que não implica qualquer modificação da prática.

8 Importa portanto, se queremos colocar a todos o problema da orientação profissional assente em dados verdadeiros, definir o que se entende por «aptidões».

9 Além do seu sentido geral a palavra aptidão pode ser aplicada a casos particulares: não manteremos senão aquele em que significa «disposição natural para ...». Para nós uma aptidão será uma disposição natural para exercer convenientemente um ofício. Mas o que é uma disposição natural? Julgamos que é uma configuração orgânica que pode ser constatada quer anatomicamente, quer fisiologicamente, quer psicologicamente. É assim que uma altura de $1,60 \mathrm{~m}$ ou um peso de 40 quilos constituem disposições naturais: uma para ser soldado, outra para ser jockey. Uma boa capacidade e bom índice respiratório serão disposições naturais do indivíduo para exercer ofícios que obriguem a trabalhar em ambientes confinados ou com materiais tóxicos. Para os ofícios que exigem força (muscular) é necessário possuir, além de músculos possantes, órgãos de eliminação das toxinas em bom estado de funcionamento. Enfim, com a aplicação de testes mentais ou psico-motores determina-se a disposição natural dos aprendizes para o exercício de profissões mais complexas.

10 A pesquisa das disposições naturais da ordem das funções mentais pareceu impossível durante longo tempo. Mas desde que Binet consagrou o fim da sua vida ao estudo objetivo da inteligência a questão ganhou precisão e foi-lhe introduzida a noção de medida.

11 O problema das disposições naturais - que vai permitir-nos abordar com mais segurança o das aptidões - pode remeter-nos para estes dois pontos da pesquisa:

$121^{0}$ - As funções mentais são independentes umas das outras? Podemos portanto, somando os resultados dos testes ter uma indicação precisa sobre o valor de uma criança para uma dada profissão?

$132^{\circ}$ - Ou devemos então fazer intervir - com ou sem esta noção de testes independentes a ideia de uma inteligência geral que domina as aptidões particulares? 
Sem entrar no pormenor das teorias relativas à influência recíproca das diversas funções podemos remetê-las para duas teses essenciais:

- A primeira é a de Thorndike segundo a qual a inteligência é composta por faculdades justapostas mas independentes. A consequência desta conceção da inteligência é a de que um teste que mede uma aptidão característica não tem correlação com os testes que medem aptidões diferentes - salvo talvez em certos casos de vizinhança muito estreita.

- A segunda é a de Spearmann segundo a qual possuiríamos além de funções mentais particulares uma inteligência geral capaz de agir sobre aquelas. $O$ que tem por consequência levar-nos a crer que testes que se aplicam a funções vizinhas têm correlações muito estreitas e permitem conhecer o valor de extensos territórios psicológicos homogéneos.

Para avaliar de forma justa estas duas teses é necessário considerar que os seus autores colocaram-se em dois pontos de vista diferentes: um, Thorndike, trabalha com elementos da inteligência e o outro, Spearmann, sobre os resultados de um complexo.

Ora o complexo, como sabemos, não tem necessariamente as qualidades dos seus elementos; possui outras novas que o caracterizam: é sobre esta noção, facilmente demonstrável , que assenta a teoria evolucionista dos fenómenos de consciência.

17 A teoria de Spearmann é pois mais exacta. Todavia não seria de aceitar sem algumas reservas porque o seu autor admite que existem correlações muito frequentes $\mathrm{e}$ estreitas entre funções notoriamente diferentes - tais como, por exemplo, a discriminação das sensações e o modo de triunfar na vida.

18 No que respeita ao facto novo, enquanto Thorndike o nega, Spearmann liga-o estreitamente aos fatores elementares que lhe deram origem. Ora, do ponto de vista da prática - que fomos chamados a originar para reconhecer as aptidões - ambos estão errados porque uma função não atinge todo o seu valor senão considerando-a na sua relação com a inteligência geral. Mas esta relação de dependência não deve ser tão estreita e tão fixa que se possam estabelecer facilmente, como pretende Spearmann, leis estritas. De facto, é preciso lembrar que há casos em que a função requer ser julgada isoladamente, porque nem sempre segue o órgão.

Para nós haverá sempre oportunidade para determinar o valor da inteligência geral ao mesmo tempo que a das funções particulares. Porque uma reage com as outras.

Assim, nas experiências feitas em sujeitos escolhidos ao acaso e em estudantes, encontra-se frequentemente uma superioridade nas atividades mentais em pessoas que não se dedicaram a cultivar o seu espírito, mas cuja inteligência é superior à dos especialistas. É assim que quando Munsterberg aplicou o seu teste de seleção dos guarda-freios aos empregados de uma companhia de transportes e a estudantes da Universidade de Harvard, constatou que estes últimos apresentavam, nos resultados do teste, superioridade em relação aos primeiros. A inteligência geral reforça portanto, em muitos casos, as atividades particulares. Parece produzir-se uma espécie de fenómeno de suplementação que facilita a adaptação.

21 A determinação de disposições naturais deve pois incidir:

- por um lado nas funções elementares cujo valor caracteriza a superioridade numa dada profissão e por outro na inteligência geral do sujeito.

Isto permite-nos alcançar esta definição das aptidões que são, na nossa opinião: disposições naturais que se reconhecem por respostas motoras ou mentais - mensuráveis - a estímulos definidos. A inteligência geral entra no quadro das aptidões. 


\section{Chamaremos aptidões profissionais:}

- as disposições naturais assim definidas cujos valores são da ordem dos valores tipo reconhecidos no operário de elite.

24

Esta definição apresenta uma dificuldade na aplicação, ou sobretudo um perigo para o qual devemos, para terminar, chamar a atenção dos conselheiros vocacionais.

25 Mue a inteligência geral agia como um fator de aperfeiçoamento nas diversas atividades especiais - especificamente profissionais - exercidas pelo homem. Parece portanto que os homens mais inteligentes podem ser atribuídos indiferentemente a estes ou aqueles ofícios. Constata-se frequentemente, com efeito, na prática, que sujeitos bem dotados intelectualmente apresentam aptidões para profissões diversas, o que facilita a sua orientação. Perante este facto impõe-se uma conclusão: a fim de não obstruir com sujeitos de elite as profissões que exigem um número restrito de aptidões especiais ter-se-á que dar lugar a uma procura, para os mais dotados, da profissão da ordem mais elevada em que possam ter sucesso, quer dizer, que exija além do acréscimo de aptidões especiais, o máximo de inteligência. 